\title{
Gonalgia na criança e no jovem adolescente em Medicina Familiar
}

Monika Furriel Thüsing*

\section{RESUMO}

A gonalgia é uma queixa comum na criança e no adolescente e esta é uma razão frequente para os pais levarem os seus filhos a uma consulta. A prevalência da dor no joelho é considerável, mas só ocasionalmente o joelho apresentará uma lesão que leve a uma intervenção cirúrgica. Por este motivo, é muito importante perceber que tipo de dor no joelho nos é referida.

É importante saber que há diferenças significativas entre o joelho de uma criança (ou do adolescente) e o joelho de um adulto.

O objectivo deste artigo é fornecer uma linha de abordagem prática na avaliação e no tratamento da dor no joelho da criança e do adolescente.

Palavras-Chave: Joelho; Dor; Criança; Adolescente; Medicina Familiar

\section{INTRODUÇÃO}

A dor do joelho é uma razão frequente para os pais levarem os seus filhos ao médico. Normalmente, o primeiro médico ao qual recorrem é o médico de família. A gonalgia na criança e no adolescente é frequente por estes hipersolicitarem os joelhos; o resultado é um quadro doloroso, muitas vezes relacionado com o crescimento.

Como Fairbank diz: «Adolescentes com dores nos joelhos participam em e gostam de actividades desportivas mais do que os que não referem dores, no mesmo grupo etário. Por isso o factor dominante na etiologia da dor anterior do joelho em adolescentes é o sobreuso, mais do que a má mecânica.»1

Hoje em dia, existe uma maior preocupação social em relação ao sucesso no desporto. O número de crianças e de adolescentes que praticam desporto com elevada intensidade para conquistar o seu próprio sonho (ou, por vezes, o sonho dos pais e dos treinadores), tem vindo a aumentar. Esta pressão interna e/ou externa promove o sobreuso das estruturas osteo-articulares.

O joelho da criança e do adolescente tem diferenças, no aspecto anatómico e fisiopatológico em relação ao

*Médica Especialista em Ortopedia

Serviço de Ortopedia, Hospital Da Estefânia, Lisboa, Portugal de um adulto, o que se traduz numa reacção diferente dos tecidos ao exercício, ao excesso do mesmo e a um eventual traumatismo.

Existe um desequilíbrio entre o crescimento do osso e o do músculo, sendo o do osso mais rápido, e pondo, assim, as estruturas à volta do osso sob tensão; isto traduz-se num aumento da força de tracção nas inserções dos tendões e justifica a tendência para aumento das lesões por sobreuso e por traumatismos.

Lidar com a dor do joelho no jovem inclui:

- aperceber-se da causa do aparecimento da dor (cada caso é um caso e a quantidade de esforço que provoca uma dor numa criança pode não ter as mesmas consequências noutra criança);

- chegar ao diagnóstico correcto;

- tentar evitar uma intervenção cirúrgica, prevenindo a cronicidade e agravamento das lesões;

- perceber os conflitos entre os pais e o jovem e as necessidades psicológicas do jovem.

Muito importante é, também, ter a noção que as doenças da anca podem, muitas vezes, causar dor no joelho (Hilton's Law). John Hilton (anatomista britânico) descreveu que a inervação do membro inferior comporta ramos sensitivos que abarcam ambas as articulações, anca e joelho; este facto explica que a dor resultante de patologia da anca pode ser referida apenas ao 
joelho, confundindo, assim, o diagnóstico.

Por isso, é indispensável fazer uma breve anamnese sobre problemas/dores na anca e, simultaneamente, examiná-la. .

\section{ANATOMIA DA CRIANÇA E DO ADOLESCENTE}

A articulação do joelho é formada por 3 ossos que articulam entre si (fémur, tíbia e rótula), dois meniscos, que ficam instalados entre o fêmur e a tíbia, ligamentos que ficam do lado interno e externo do joelho (ligamento colateral interno e externo) e ligamentos que se cruzam dentro do joelho (ligamento cruzado anterior e posterior). Lesões de qualquer destas estruturas podem causar dor no joelho.

O joelho da criança e do adolescente tem diferenças nos aspectos anatómico e fisiopatológico em relação ao joelho de um adulto, que se traduzem numa reacção diferente dos tecidos ao exercício, ao excesso do mesmo e a um eventual traumatismo.

Em comparação com o adulto, a criança e o adolescente têm articulações mais móveis, ossos maleáveis e cartilagens de crescimento físárias e apofísárias abertas.

Existe um desequilíbrio no balanço entre o crescimento ósseo versus o crescimento muscular. O osso cresce mais depressa que o músculo, razão pela qual as estruturas à volta do osso ficam sob tensão e há um aumento da força de tracção nas inserções dos tendões, o que contribui para a tendência para lesões traumáticas e não traumáticas.

Por esta razão surgem, a longo prazo, as alterações estruturais no aparelho osteoarticular e, também, as alterações da resposta a um traumatismo agudo ou repetitivo.

Muitas lesões no jovem são causadas por sobre-uso; a sujeição a forças de tensão/tracção, de compressão, de cisalhamento ou compostas pode acabar por afectar as estruturas esqueléticas.

Torna-se, por isso, importante saber as diferenças mais evidentes entre as várias estruturas, na criança e no adulto, para poder fazer um diagnóstico correcto. Assim, na criança encontra-se:

- presença de cartilagens de crescimento distal do fémur, proximal da tíbia e do peróneo ${ }^{1}$

- maior espessura da cartilagem articular;

- desenvolvimento da rótula a partir de um único núcleo de crescimento (em caso de mais núcleos, há a

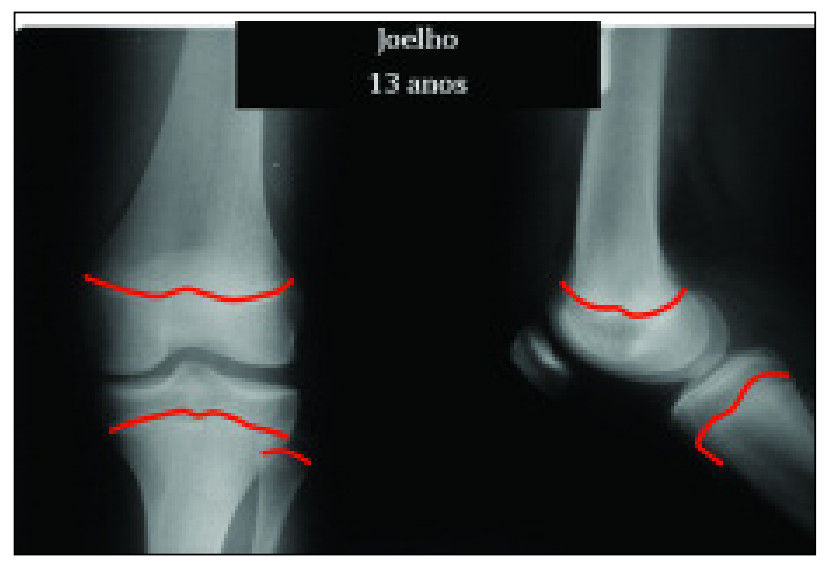

Figura 1. Radiografia em a.p. e perfil de um joelho de um adolescente de 13 anos de idade, com as linhas das cartilagens de crescimento marcadas (arquivo da autora)

possibilidade de a rótula evoluir para uma rótula biou multipartita);

- osso em formação e crescimento (em espessura e longitudinal), sendo o osso cortical menos espesso, o que implica que o osso infantil seja menos duro, resultando daí fracturas típicas da criança (fractura helicoidal do fémur, por exemplo).

\section{SEMIOLOGIA CLÍNICA}

Na avaliação do joelho existem dados a que se deve dar especial atenção:

\section{História clínica / Anamnese:}

- Motivo da consulta

- Início das queixas (início espontâneo, sem traumatismo; se houve traumatismo - como aconteceu...)

- Tipo de dor (constante, mecânica, em repouso, nocturna, etc.)

- Progressão das queixas

- Antecedentes pessoais: doenças prévias, antecedentes traumáticos

- Hábitos desportivos

\section{Exame objetivo:}

Devem sempre comparar-se os resultados obtidos no joelho lesado com os do joelho oposto.

1. Observação geral:

- estrutura geral do jovem, peso e altura, pois podem ter influência nas condições mecânicas e no braço de 
alavanca do membro;

- observação da marcha;

- desmetrias dos membros inferiores;

- deformidades dos membros inferiores (genu valgo ou genu varo);

- encurtamento muscular / tensão nas inserções tendinosas;

- existência de atrofias musculares localizadas;

- hiperlaxidão ligamentar.

2. Observação mais específica do joelho:

- aumento de volume do joelho, temperatura, rubor;

- derrame intra-articular;

- ponto doloroso à palpação óssea/articular;

- mobilidade activa e passiva do joelho;

- bloqueio articular;

- testes meniscais (menisco interno e externo);

- testes ligamentares (ligamento colateral interno e externo, ligamento cruzado anterior e posterior);

- testes da rótula.

Na presença de muitos testes diferentes para examinar as estruturas acima mencionadas, limito-me a fazer uma escolha pessoal, não querendo minimizar os restantes testes.

\section{Rótula}

\section{«Dancing patela» (choque da rótula)}

- uma mão espreme o recesso superior e, ao mesmo tempo, a outra mão pressiona a rótula contra o fémur;

- quando se sente a patela a 'dançar', é sinal da existência de um derrame intra-articular.

\section{«Glide test»}

- segurar com uma mão o pólo superior e com a outra o pólo inferior da rótula;

- fazer deslizar a rótula para lateral sobre o côndilo externo e para medial sobre o côndilo interno;

- permite comparar o deslizamento lateral com o medial, sentir diferenças de tensão entre o retináculo interno e externo (estruturas capsulo-ligamentares femuro-rotulianas) e sentir o sinal de apreensão («medo de luxação da rótula»).

\section{«Tilt-test»}

- retináculo externo retraído: a faceta externa da rótu- la desce lateralmente e vai contra o côndilo externo do fémur;

- retináculo externo laxo: a rótula «sobe» do lado externo e sai da tróclea.

\section{Menisco}

\section{Steinmann I/II}

- Fixar o joelho e fazer rotação forçada da perna (I), com vários graus diferentes de flexão (II);

- Dor medial com rotação externa sugere lesão do menisco interno;

- Dor lateral com rotação interna sugere lesão do menisco externo.

\section{Apley}

- decúbito ventral com o joelho em $90^{\circ}$ de flexão, fixação da coxa na marquesa;

- rotação interna e externa do joelho, uma vez a fazer tracção do joelho e outra a fazer compressão do joelho contra a marquesa.

\section{Ligamentos colaterais}

- Stress em valgo para o ligamento colateral interno em extensão completa e $20^{\circ}$ de flexão (para relaxar a cápsula posterior e o ligamento cruzado posterior);

- Stress em varo para o ligamento colateral externo em extensão completa e $20^{\circ}$ de flexão.

\section{Ligamentos cruzados:}

\section{Lachman}

- Decúbito dorsal, joelho em 15 a 30º de flexão;

- uma mão segura o fémur, a outra puxa a tíbia para anterior;

- 3 Graus de instabilidade descritos:
- até $3 \mathrm{~mm}$
normal
$-<5 \mathrm{~mm}$
Grau I ou (+)
- 5-10 mm
Grau II ou (++)
- >10 mm
Grau III ou (+++)

$\rightarrow$ clinicamente não é fácil distinguir estes graus de instabilidade, sendo mais fácil a diferenciação de instabilidade sim/não, com sensação de toque duro ou mole no final do exame.

\section{Teste de Pivot}

- Decúbito dorsal, uma mão imobiliza do lado externo o fémur, a outra segura a tíbia; 
- manter a perna em rotação interna e abdução ('valgus stress'), nesta posição o joelho é trazido da extensão para a flexão;

- em caso de haver uma rotura do ligamento cruzado anterior surge uma subluxação da tíbia para anterior.

\section{EXAMES COMPLEMENTARES DE DIAGNÓSTICO}

\section{Imagiologia}

Os exames a pedir são

- radiografia do joelho em dois planos (antero-posterior e perfil);

- radiografia da rótula em perfil;

- por vezes, radiografia axial da rótula a $30^{\circ}$ e a $60^{\circ}$ de flexão.

Neste contexto, não se pode esquecer que, numa criança ou num adolescente, depois de um traumatismo articular pode não haver alterações facilmente visíveis na radiografia, o que não significa que não haja arrancamentos ou pequenas fracturas na zona da cartilagem.

Acessoriamente, em caso de suspeita de outras patologias, poderão ser pedidas:

- Ecografia articular

- Tomografia axial computorizada (TAC)

- Ressonância magnética nuclear (RMN)

- Cintigrafia óssea (actividade metabólica óssea)

Em caso de derrame intraarticular, a punção articular pode ser uma mais valia na formulação do diagnóstico. O líquido pode ser seroso, serohemático, hemático, hemático com gotas de gordura e, com essas características, indicar um diagnóstico (por exemplo, fractura osteocondral).

\section{BREVE REVISÃO DE ALGUMAS ALTERAÇÕES QUE CAUSAM DOR NO JOELHO NA CRIANÇA E NO ADOLESCENTE}

\section{Osteocondroses}

As osteocondroses constituem um amplo e heterogéneo grupo de alterações, caracterizado por transtorno da ossificação encondral das epífises ou apófises.

Manifestam-se por dor de carácter mecânico e estão relacionadas com os surtos de crescimento e de alterações hormonais. As osteocondroses têm uma origem desconhecida. Historicamente, são classificadas como necroses isquémicas e são conhecidas pelo nome do autor que descreveu cada uma das suas localizações.
Pensa-se que o aumento das acções mecânicas ou traumatismos sobre uma região com predisposição serão responsáveis pelo aparecimento da lesão.

\section{Osteocondroses no joelho:}

\section{Doença de Osgood Schlatter}

- idade: 11 aos 16, distribuição masculino/ feminino $1: 1$

- situada na tuberosidade anterior da tíbia

Doença de Sindling-Johannson-Johansson

- idade: 10 aos 15, distribuição masculino/ feminino $1: 1$

- situada no pólo inferior da rótula

\section{Princípios terapêuticos:}

- Identificação das causas e sua minimização;

- Alívio da tensão muscular (palmilhas, joelheira...);

- Alongamentos musculares;

- Restrição da actividade física por períodos relativamente longos (mais de 3 meses, até desaparecimento total de toda a sintomatologia).

\section{Prevenção:}

- Manter um bom equilíbrio músculo-tendinoso;

- Alívio da tensão muscular (palmilhas, joelheira...);

- Tentar descobrir o jovem em risco para poder intervenir precocemente;

- Alertar o jovem para a existência desta patologia e estimulá-lo a fazer treinos de forma equilibrada e controlada.

\section{Osteocondrite dissecante}

A osteocondrite dissecante é uma necrose asséptica localizada, que afecta o osso subcondral com maior frequência na região lateral do côndilo femural interno, podendo, também, estar localizada no côndilo lateral e, por vezes, na face posterior da rótula.

A etiologia exacta não está esclarecida: discutem-se razões traumáticas e factores hereditários. Existe uma disrupção da vascularização de uma área localizada do osso subcondral, da qual resulta a necrose focal.

A idade do adolescente no início da osteocondrite dissecante tem um valor prognóstico. Segundo D. Wenger $^{2}$ as crianças que, no início, têm menos de 12 anos, têm lesões muitas vezes mais pequenas e apresentam uma maior probabilidade de ter uma resolução espon- 


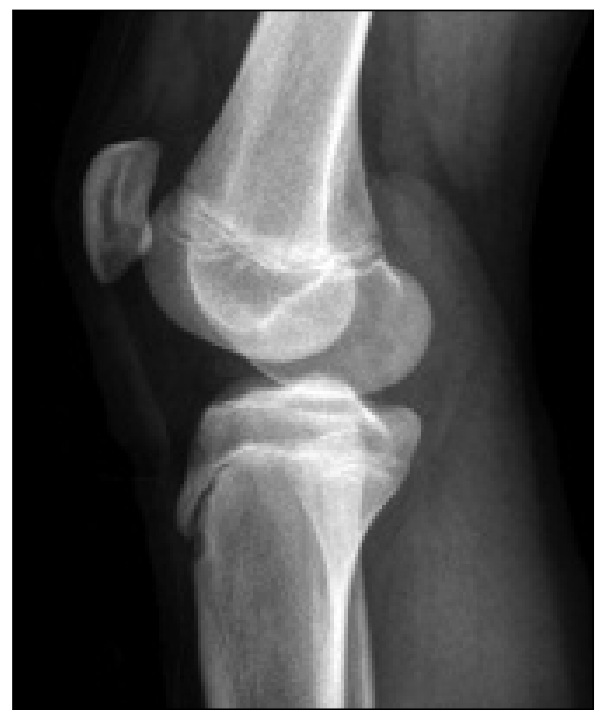

Figura 2. Radiografia em perfil de um joelho, alterações da tuberosidade anterior da tíbia (arquivo da autora)

tânea. Adolescentes com mais de 12 anos de idade e aqueles com lesões maiores de dois centímetros têm um potencial para fazer uma separação parcial ou até mesmo um descolamento do fragmento.

Os sintomas são, em regra: dor inespecífica, podendo haver a sensação de um clique ou ressalto, e um aumento moderado de volume do joelho. No caso do fragmento estar deslocado, existe um corpo livre dentro do joelho que pode causar o bloqueio do mesmo.

Para obter o diagnóstico é feita a anamnese e, geralmente, a radiografia convencional basta, talvez adicionando uma imagem de Frick (imagem AP do joelho em flexão, que permite interpretar a zona intercondiliana).

O tratamento é, na maior parte dos casos, conservador, passando pela diminuição da actividade física; por vezes é necessária a descarga do membro afectado com duas canadianas. No caso de o fragmento se ter solto, o tratamento será cirúrgico.

\section{Luxação da rotula}

Neste contexto é preciso distinguir a luxação aguda da rótula por um traumatismo adequado, que é uma situação mais rara, da luxação rotuliana aguda por predisposição, sem traumatismo major ou mesmo sem traumatismo nenhum. Neste último caso, os jovens não conseguem, geralmente, explicar como aconteceu a luxação, referindo que o joelho simplesmente «falhou».
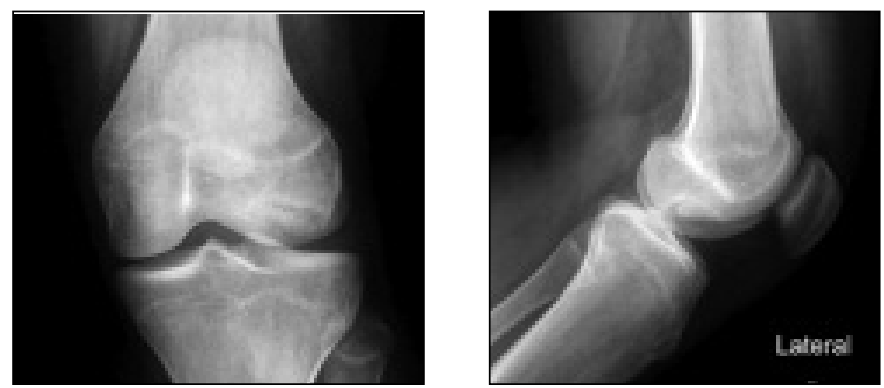

Figura 3. Radiografia em dois planos de um joelho, Osteocondrite dissecante (arquivo da autora)

Os casos com predisposição podem desenvolver instabilidade crónica, com luxações recidivantes.

\section{Lesão meniscal}

Em comparação com o adulto, é rara a lesão do menisco na criança e no adolescente. Quando há uma lesão do menisco interno, ela é, normalmente, extensa e divide-se em lesões do tipo «asa de cesto» ou em «roturas na base», que devem, sempre que possivel, ser suturadas (o menisco do jovem tem irrigação sanguínea na base do menisco; o adulto, por norma, já não tem).

A lesão do menisco externo é, na maior parte das vezes, ligada à presença de um menisco discóide. $\mathrm{O}$ menisco discóide é um menisco de forma redonda, em vez de ter a forma de meia lua.

\section{Lesão do ligamento colateral}

A lesão do ligamento colateral externo é muito rara; já a lesão do ligamento colateral interno é mais comum. O tratamento é conservador. Esta lesão pode estar relacionada com a lesão do ligamento cruzado anterior e do menisco interno («unhappy triad»), tendo o joelho indicação cirúrgica (o ligamento colateral interno continua a ser tratado de modo conservador).

\section{Lesão do ligamento cruzado anterior}

$\mathrm{Na}$ criança e no adolescente a lesão mais típica por stress do ligamento cruzado anterior é a fractura da espinha tibial, que corresponde à inserção distal do ligamento cruzado anterior. Estas fracturas podem ser tratadas com gesso se o fragmento estiver reduzido; se não estiver, é necessário fazer uma redução e fixação do fragmento.

No jovem, a lesão do ligamento cruzado anterior iso- 
lada e incompleta tem potencial para regenerar. A lesão completa isolada pode ter tratamento conservador ou cirúrgico. O prognóstico desta lesão na criança é pior que no adulto, por um lado pela maior actividade física, por outro, pela laxidão ligamentar típica da criança que, por si, dá uma maior instabilidade ao joelho. Por esta razão, o tratamento é, cada vez mais, cirúrgico. $\mathrm{Na}$ lesão do ligamento cruzado anterior com lesão de mais estruturas, o tratamento deverá ser cirúrgico.

A técnica cirúrgica no adolescente difere da do adulto, enquanto as cartilagens de crescimento ainda não estiverem fechadas.

\section{Fracturas}

A fractura de um osso de uma criança tem características especiais, tanto

- no tipo de fractura,

- como no processo de consolidação,

- no tempo que este leva e

- nas complicações que podem resultar.

O osso infantil é menos rígido que o osso do adulto, resultando daí fraturas típicas da criança. As fracturas articulares deverão ser reduzidas anatomicamente e assim ser mantidas por meios incruentos ou cruentos.

\section{Infecções}

Neste contexto, é preciso dar especial atenção às artrites sépticas, que são uma situação grave, com alta morbilidade. Podem surgir em qualquer idade: $30 \%$ dos casos ocorrem antes dos 2 anos e $50 \%$ antes dos 3 anos.

Do ponto de vista anatómico, o joelho é a articulação mais frequentemente atingida depois dos 2 anos; antes dessa idade, nomeadamente no recém-nascido, é a anca. O total destas 2 áreas abarca $85 \%$ de todas as artrites na criança.

A criança apresenta-se com ar «doente», geralmente com febre, sem apetite, irritada e prostrada. A articulação do joelho perde os contornos ósseos, demonstra um aumento da temperatura local e rubor, derrame articular e limitação dolorosa da mobilidade.

Existem várias vias pelas quais os agentes infecciosos podem atingir uma articulação:

- Via hematogénea (é a mais frequente, em mais de $80 \%$ dos casos);

- Disseminação de uma osteomielite na proximidade;

- Infecção periarticular;
- Medidas diagnósticas ou terapêuticas (iatrogenia);

- Feridas perfurantes.

A flora responsável varia com o escalão etário, sendo essencial fazer uma tentativa de isolamento do germe em causa antes do início de um tratamento antibiótico.

No recém-nascido, o quadro clínico é, por vezes, menos claro, e o único achado positivo pode ser uma pseudo-paralisia de um membro.

A osteomielite distal do fémur e proximal da tíbia também podem causar dor referenciada ao joelho.

\section{Tumores}

Quase 40\% dos tumores ósseos da criança e do adolescente encontram-se na região do joelho, principalmente no fémur distal e na tíbia proximal, onde estão localizadas as cartilagens de crescimento mais activas do corpo. ${ }^{3}$ Por este motivo, e embora raros e mais frequentemente benignos (osteocondroma, por ex.), é necessário não esquecer esta possibilidade.

\section{PROCEDIMENTOS DO MÉDICO DE FAMÍLIA}

A longo prazo, a maioria dos casos de crianças e adolescentes que referem dor no joelho não apresentam repercussões funcionais. Por este motivo, é importante chegar ao diagnóstico correcto, para não haver um sobre-tratamento dos casos que podem ser tratados de forma relativamente simples. Por outro lado, também não devem escapar os doentes com um diagnóstico que necessita de tratamento mais cauteloso.

O tratamento após um traumatismo agudo deve incluir descarga do membro afectado com o uso de 2 canadianas, a elevação do membro, crioterapia local, contenção local e AINE em SOS. Estas medidas devem ser respeitadas até à ausência de dor.

No caso de a criança não deixar examinar o joelho após o traumatismo, deve ser reavaliada em tempo útil (2-3 dias). Em caso de dúvida, deve ser encaminhada para um Ortopedista.

Os casos em que há suspeita de lesão do joelho ou os casos em que há um quadro álgico significativo deverão ser encaminhados para um serviço de Urgência.

\section{CONCLUSÕES}

Existem muitas crianças e adolescentes, de todas as idades e de ambos os sexos, com dor no joelho de todo 
o tipo de intensidade. As causas mais comuns estão relacionadas com o stress por actividade em excesso e com o crescimento, não necessitando de exercícios de recuperação específicos extensos nem de intervenção cirúrgica.

A função do médico é a de analisar com atenção a história clinica, examinar o joelho, fazer as radiografias necessárias (o mínimo possível) e excluir doenças da anca, estabelecendo um diagnóstico. Na maior parte das vezes, basta dar uma explicação ao jovem e aos pais sobre o diagnóstico, as suas causas, o prognóstico e o plano terapêutico, de forma a que a criança ou o adolescente possam «crescer» sem queixas e/ou sem sequelas.

Para isso, o médico tem sempre que ter em mente as diferenças existentes na criança e no adolescente (com as diferenças inerentes no possível diagnóstico), tanto do fôro ortopédico como traumatológico.

Alguns casos necessitam de auxílio por ortóteses, fi- sioterapia e, também, de limitação da actividade física.

No entanto, outros casos requerem tratamento específico ou, até, intervenção cirúrgica. São estes os que é necessário detectar e que deverão ser encaminhados para um serviço de Ortopedia.

\section{REFERÊNCIAS BIBLIOGRÁFICAS}

1. J. Fairbank JC, Pynsent PB, van Poortvliet JA, Phillips H. Mechanical factors in the incidence of knee pain in adolescents and young adults. J Bone Boint Surg Br 1984 Nov; 66 (5): 685-93.

2. Wenger DR, Rang M. The Art and Practice of Children's Orthopaedics. New York: Raven Press; 1993.

3. Hefti F. Kinderorthopädie in der Praxis. Berlin: Springer Verlag; 1997.

Os autores declararam não possuir conflitos de interesses

\section{ENDEREÇO PARA CORRESPONDÊNCIA}

Monika Furriel Thüsing

Serviço de Ortopedia, Hospital Da Estefânia

Rua Jacinta Marto, 1169 Lisboa, Portugal

E-mail: monikathuesing@gmx.de

\section{ABSTRACT}

\section{KNEE PAIN IN CHILDREN AND ADOLESCENTS IN FAMILY MEDICINE}

Often, children and adolescents complain of knee pain, leading parents to take them to a clinical consultation with their family physician. The frequency of knee pain is considerable but only occasionally does the knee have an injury that needs surgery. Therefore it is very important to understand what type of knee pain is being referred.

It is also important to know that there are significant differences between the knee of a children (and an adolescent) and that of an adult.

The goal of this article is to outline a practical approach for the evaluation and treatment of knee pain in children and adolescents.

Keywords: Knee; Pain; Child; Adolescent; Family Medicine 